\title{
¿ENSEÑAMOS Historia? \\ Reflexiones sobre la Práctica Pedagógica
}

\author{
Do We Teach History? \\ Reflections About Pedagogical Practice
}

\author{
Pablo Aravena Núñez \\ Especialista en Teoría Historiográfica \\ Universidades de Viña del Mar y de Valparaíso \\ Agua Santa 7055, Rodelillo, Viña del Mar \\ paravena@uvm.cl
}

Resumen: El presente texto pretende problematizar la enseñanza de la historia, proponiendo como hipótesis que la especificidad de la historia, en tanto disciplina (historiografía), es diluida en las estrategias 'didácticas' más extendidas entre los profesores. Este extravío es digno de investigar no por un mero celo disciplinario, sino debido a las consecuencias que puede tener en las valoraciones, decisiones y acciones futuras de los alumnos. Se plantea que la construcción de una representación del mundo histórico, como la que se delinea a partir de las actuales prácticas pedagógicas, no hace más que reforzar ciertas ideas arraigadas en el sentido común, impidiendo cualquier cambio conceptual y desestimando la historicidad de los propios estudiantes.

Palabras clave: Historiografía, didáctica, sentido común, historicidad.

Abstract: The aim of this paper is to problematize the teaching of history, advancing the hypothesis that the specificity of history as a discipline (historiography) is dilute $\mathrm{d}$ by the 'didactic' strategies most widespread among teachers. This distortion is worth investigating not for a mere disciplinary zeal, but for the consequences it might have on the pupils' value judgements, decisions and future actions. It is claimed that the construction of a representation of the historical world as outlined by current teaching practices amounts to a mere reinforcement of deep-seated common sense ideas, thus preventing any kind of conceptual change and disregarding the historicity of the pupils themselves.

Keywords: Historiography, methodology, common sense, historicity. 


\section{INTRODUCCION}

"El engaño ahora no reinaría en la calle $o$ en los medios de comunicación, sino que se produciría ya desde la sropias a ulas".

Carlos Martinez-Shaw

La presente reflexión se articula a partir de tres experiencias particulares del autor. En orden cronológico: a) el desarrollo de una asignatura de 'Introducción a la Historia', para alumnos de primer año de carreras de ingeniería (Valparaíso, 2002-2009), como también de Historia y Ciencias Sociales (Valparaíso, 2007-2010); b) la supervisión de prácticas profesionales de alumnos de último nivel de Pedagogía en Historia y Geografía (Valparaíso, Viña del Mar, Quilpué, Villa Alemana, 2007-2010), y c) el desarrollo de diversos módulos en el contexto de Programas de Apropiación Curricular y Postítulo con profesores dedicados a la enseñanza de la Historia y las Ciencias Sociales (Santiago, 2009-2010).

Estas experiencias han significado un importante grado de acercamiento a las prácticas de enseñanza de la historia, tanto de la provincia de Valparaíso como de la región Metropolitana, localizadas principalmente en establecimientos subvencionados y municipalizados. El relevamiento y análisis de las ideas previas de los estudiantes de primer semestre de universidad, la observación de clases de alumnos practicantes -que en los hechos es una instancia para observar las de los profesores guías de los establecimientos- $y$ las narraciones de prácticas y experiencias educacionales de profesores de enseñanza básica y media, constituyen la materia prima de este trabajo. No obstante, debemos advertir que este material no ha sido tratado ni sistematizado, al menos de manera formal, con los rudimentos metodológicos de uso habitual en ciencias sociales, por lo que este texto no pretende ser un informe de investigación, sino un texto de interpretación y reflexión en el que se articula nuestra ocupación en problemáticas ligadas a la Teoría Historiográfica y Filosofía de la Historia, con un posterior acercamiento a las prácticas pedagógicas.

En un primer apartado expondremos aquellas ideas previas acerca del concepto de historia de estudiantes de primer semestre de universidad, junto con las reflexiones propias de quien persigue un cambio conceptual, haciendo hincapié en su sistematicidad y potencial rendimiento social. En seguida trataremos de presentar las prácticas de enseñanza de la historia de las cuales se han derivado -en gran medida- tales ideas previas, poniendo en relieve las preconcepciones involucradas en ellas. Luego desarrollaremos las 
operaciones que definen la especificidad de la historiografía desde su constitución disciplinaria (s. XIX). En este punto la intención será brindar un medio de contraste que nos permita identificar los vicios que acompañan la enseñanza de la historia, como visualizar la potencialidad de un saber, tanto en términos estrictamente intelectuales (comprensión de lo real), como políticos en el sentido más general y primario del concepto (organización y construcción de proyectos para incidir en lo real). Finalmente formularemos algunas observaciones finales que pretenden describir una experiencia didáctica orientada hacia el cambio conceptual requerido para la comprensión de lo histórico.

\section{IDEAS PREVIAS: LA NATURALIZACIÓN DE LO HISTÓRICO $\stackrel{1}{ }$ /}

El tratamiento de ideas previas sobre el concepto de historia, a nivel escolar, ha sido materia de diversos estudios (Rosa Rivero, 2004; Carretero, 2007b). En nuestro caso la apuesta que lleva el relevamiento de tales ideas en alumnos de primer nivel universitario, es la de evidenciar la sedimentación cultural de las prácticas escolares de enseñanza de la historia que, desde luego, deben ser puestas en relación con otras representaciones disponibles en el mercado simbólico (Bourdieu, 1991) que caracterizan la cultura del Chile contemporáneo.

Contemplando los estudios aludidos, hemos optado por conceptualizar el fenómeno tratado como una dimensión problemática particular del problema más vasto que significa la articulación entre Naturaleza e Historia a nivel cognitivo. Aunque en términos de los avances de la filosofía contemporánea la contraposición frontal de estos campos difícilmente tiene validez (pues ya no es posible postular la existencia de un campo de determinación absoluta frente a otro de libertad absoluta) (Cruz, 1986), a nivel de las representaciones sociales de los alumnos, o del sentido común en general, no deja de constatarse su permanencia. En estricto rigor el problema no lo constituye tanto la disyunción como la subsunción de un campo en otro: el ocultamiento y la incomprensión de la historicidad de lo social cuando sus estructuras son identificadas como algo dado, inmodificable, natural.

Nuestro planteamiento al enfrentarnos a las ideas previas de los estudiantes ha sido el de cómo generar una cabal comprensión de esta dimensión fundamental de lo social y de la cultura. Cómo lo que usualmente se tiene por natural, eterno, necesario o 'ajustado al orden' es en realidad una construcción histórica, un 'artificio' humano que dista mucho de ser algo definitivo. La comprensión de la historicidad de lo social se cumpliría a 
cabalidad no cuando el alumno entiende el pasado como una sucesión de momentos sociales provisorios a ser modificados o superados, sino cuando éste capta su propio presente como un momento social dentro del cual está él mismo: el presente como algo 'dado' (en gran medida humanamente producido) pero a la vez como un campo de posibilidades.

El problema ha sido recurrente cuando las ciencias sociales se han ocupado de los fenómenos de dominación o hegemonía cultural. La naturalización ( $\mathrm{u}$ ontologización) del presente suele ser una estrategia recurrente de los discursos ideológicos. Así nos lo recuerda Pierre Bourdieu a propósito de los problemas que debe afrontar el sociólogo en su oficio, rescatando el planteamiento original de Marx: "Marx demostró repetidamente que cuando las propiedades o las consecuencias de un sistema social son atribuidas a la naturaleza es porque se olvida su génesis y sus funciones históricas, es decir todo aquello que lo constituye como sistema de relaciones; más exactamente, Marx señala que el hecho de que este error de método sea frecuente se debe a las funciones ideológicas que cumple al lograr, por lo menos imaginariamente, eliminar la historia". (Bourdieu, 1994, p. 167). He aquí un postulado sobre el que volveremos al final de este trabajo.

Sin embargo, este planteamiento no agota la complejidad del fenómeno. Los actuales estudios de enfoque cognitivo, aplicados a la enseñanza de la historia y las ciencias sociales, han mostrado también que la representación del mundo histórico y social "está sometida a variaciones de naturaleza evolutiva que no es posible soslayar" (Carretero y Pozo, 1984, p. 47). Es decir, que la edad de los niños está asociada -aunque no en términos absolutosa ciertos límites cognitivos para la captación de la historicidad de lo social. Según los estudios de Mario Carretero, los adolescentes hasta los 15 o 16 años (o más tarde aún), suelen entender "que las cosas son como son y que apenas pueden modificarse, esto es, no pueden concebir cabalmente la historia" (Carretero, 2007a, p. 10). En efecto, la idea de cambio social o dinamismo de la sociedad -por ejemplo, las instituciones que cambian aún conservando su identidad- o la idea misma de continuidad en el acontecer, es decir, que 'el presente es consecuencia directa del pasado y será -o está siendo ya- causa del futuro', es una de las más tardías y complejas evolutivamente, lo cual ha llevado a plantear la incómoda pregunta de ¿para qué enseñar historia en las escuelas si los límites cognitivos para su cabal comprensión suelen rebasarse a una edad no escolar? (Carretero y Pozo, 1984).

Para las ciencias sociales la complejidad del fenómeno se ha revelado cuando se ha hecho evidente que gran parte de su producción teórica e investigaciones empíricas iba en dirección de dar razón a una perspectiva 
naturalista de lo social: en una primera fase (positivista comtiana) mediante el esfuerzo por dar con una legalidad social, a la que podemos sumar ciertas corrientes marxistas en busca de las leyes de la historia, el funcionalismo con su juicio sobre las lógicas sociales disfuncionales, hasta la producción del estructuralismo en su esfuerzo por dar con estructuras subyacentes, postulando a nivel epistemológico un cierto eleatismo y reduciendo al sujeto a mero soporte. Es así que desde fines de la década de los setenta se ha comenzado a plantear la vuelta o rescate del sujeto como una forma de escapar a los obstáculos epistemológicos y las implicancias políticas de los planteamientos tradicionales (Zemelman, 2001). Particularmente en historiografía los enfoques estructuralistas o demasiado estáticos (geohistóricos), provenientes de la segunda generación de la escuela de los Annales, se han ampliado o han debido ceder ante perspectivas narrativistas, culturalistas o microhistóricas que reclaman la centralidad del sujeto, de la experiencia y de lo cotidiano como campo de realización de lo histórico (Burke, 2006. Lorenz, 2007).

En lo que sigue analizaremos nuestra experiencia con las ideas previas de los estudiantes, para posteriormente tratar de proporcionar indicios para un modelo de intervención didáctica y propiciar el cambio conceptual hacia la comprensión de la historicidad social.

Aunque -como ya advertimos- los datos y referencias que utilizaremos no han sido fruto de un estudio sistemático, tienen la cualidad de estar fundados en la percepción del profesor y podrán servirnos para dar cuerpo a una descripción básica de la realidad educativa que ha de tenerse en cuenta tanto para el análisis como para un posible diseño de intervención didáctica.

Como se ha adelantado, se trata de una asignatura de Introducción a la Historia dictada a un grupo de estudiantes (30 aproximadamente) de entre 18 a 20 años, que cursan carreras de ingenierías e Historia y Ciencias Sociales (por separado). Como una manera de acceder a sus ideas previas sobre lo social y la historia como disciplina, se les interpela con diferentes tipos de planteamientos y preguntas: a) enuncien algunas de las maneras conocidas de aproximarse al pasado incluyendo lo que creen que hace la historia, b) ¿para qué sirve la historia?, c) ¿cuáles son los principales problemas que nos asedian en nuestro presente? y d) ¿qué explicación general o causas se podrían dar para entender la naturaleza de tales problemas? Las respuestas a nivel general -alcanzando en algunos grupos carácter prácticamente unánime- son: a) respecto de los modos de aproximarse al pasado: existe una diversidad de modos de visitar el pasado, además de la historia entendida como "narración de lo que ha pasado", desde las más tradicionales (leyendas, mitos, genealogías familiares, museos) hasta las más actuales (memorias, turismo, coleccionismo, 
canales temáticos de TV); b) respecto de la utilidad de la historia: las respuestas se agrupan principalmente en dos líneas -primera: la historia sirve para no cometer los errores del pasado y segunda: la historia sirve para estudiar el pasado- a las que últimamente (en los últimos tres años) se ha agregado otra, fácilmente ligable a las resonancias del discurso político y mass mediático: la historia sirve para preservar la identidad y porque quien no tiene historia no puede tener futuro; c) respecto de los problemas del presente: los más citados son pobreza, desigualdad, egoísmo, abuso de poder, corrupción; d) respecto de las causas posibles: la explicación estándar termina siendo siempre, El Hombre o La Naturaleza Humana, o sencillamente el desde siempre ha sido a sí.

Es a partir de este cuerpo de ideas generales que nos permitimos introducir el concepto de conocimiento previo tal como se define éste a partir del enfoque constructivista de José Antonio Castorina, como integrado por "una variedad de componentes, así como de una cierta sistematicidad". No obstante, debemos aclarar nuestra reserva al asumir este concepto, pues pertenece a una perspectiva epistemológica que pone en duda la posibilidad de establecer diferencias entre "las ideas del pensamiento cotidiano sobre la sociedad y lo que proponen las ciencias sociales" (Castorina, 2007, p. 12). Sostenemos que el saber disciplinario se constituye (o debe constituirse) con una racionalidad mostrable (apodicticidad), mientras las ideas de uso cotidiano son portadas acríticamente. Valoramos, en cambio -por su utilidad explicativa- otras ideas aparejadas a este concepto, como la de la heterogeneidad de sus componentes (creencias, hipótesis, representaciones sociales), su carácter sistemático y su consideración como punto de partida imprescindible para el cambio conceptual.

En efecto, sostenemos que nos encontramos frente a un cuerpo de ideas previas sobre el conocimiento histórico y lo social, las que han sido relevadas mediante preguntas distintas. Estas ideas previas dan cuenta, de manera fragmentaria, de una verdadera representación social, un sentido común que "orienta la conducta y permite la comunicación de los individuos en el mundo social" (Castorina, 2007, p. 14), dado que a partir de las respuestas a las distintas preguntas podemos establecer un grado de sistematicidad. Es lo que vemos tras un entendimiento de la actividad de la historia desligada del presente, la convicción solapada de su carácter inútil en términos vitales y el juicio sobre el carácter eterno e insuperable de los problemas del presente.

Se trata de un saber previo, definible también como conocimiento conceptual en tanto se compone de ideas bastante afianzadas mediante la experiencia cotidiana de los alumnos en el Chile neoliberal de la postdictadura, 
repleto de casos en que las realidades se imponen y no se eligen ni construyen. Las respuestas en torno a la historia y la sociedad presente dan cuenta de "la adaptación de los sujetos al medio en que viven", de manera que prestan una gran funcionalidad (Carretero, 2007, p. 48). Por otra parte habría que añadir a esto último que una concepción de lo social como la descrita arriba lleva a omitir la pregunta por la responsabilidad de los individuos en lo que acontece, que es uno de los signos más claros de su imposibilidad o renuncia a entenderse como sujetos-agentes.

La sistematicidad de estas ideas sobre la historia, lo social y el presente es lo que da consistencia a la tesis que esperamos introducir para dar sentido a un posible trabajo didáctico en pro del cambio conceptual: "el discurso de la historia es indisociable del discurso de la acción" (Cruz, 2004, p. 9), que es una tesis específica a propósito del saber disciplinario de la historia que hace pleno sentido con una tesis más básica, aunque no por ello más sencilla, que es la de la historicidad de lo social.

\section{OBSERVACIONES SOBRE LAS PRÁCTICAS DE ENSEÑANZA DE LA HISTORIA}

¿Qué tipo de prácticas han terminado por generar una comprensión de lo social como la arriba descrita? En lo que sigue trataremos de describir algunas de esas prácticas, sin pretensión alguna de agotarlas. Nos limitaremos a señalar las más extendidas y llamativas.

Pero antes de entrar en materia habrá que realizar al menos dos acotaciones. En primer lugar no pretendemos atribuir, de manera unilateral, la constitución de esa gran idea previa arriba detectada (la naturalización de lo histórico) a las mencionadas prácticas. Pues no podemos dejar de contemplar que ellas se encuentran trabadas y reforzadas por una serie de representaciones disponibles en el mercado simbólico, para lo cual los medios de comunicación cumplen una función decisiva. La subjetividad tanto de profesores como de estudiantes está cada vez más constituida por el influjo de los medios.

En segundo lugar -aunque sea considerable en ciertos casos- guardamos distancia de aquellos planteamientos que focalizan la responsabilidad de la reproducción del sentido común y preconcepciones sobre lo social en la negligencia del profesor: "un fruto de la falta de preparación científica acompañada de la falta de voluntad de actualización, de la ausencia de lecturas y de reflexión sobre la propia función como docente" (Martinez-Shaw, 2004, p. 37). Una postura tal, que centra el problema en la labor de cada docente, 
no hace más que efectuar la tan extendida -y funcional- operación retórica de usar las responsabilidades individuales como coartada de fallas estructurales fruto de una política educacional entregada a una lógica extraeducativa (economicista en lo fundamental), ocultando así las responsabilidades de los actores que la han construido. La excesiva carga laboral, los bajos sueldos y la presión que ejerce sobre la labor docente la filiación ideológica o confesional de los sostenedores de los establecimientos no pueden ser descartados del análisis como consideraciones poco elegantes. Estas últimas adquieren un rol fundamental tratándose de la enseñanza de la historia.

Pese a nuestro distanciamiento, las consideraciones del citado Carlos Martinez-Shaw sobre las prácticas más extendidas se nos presentan como una taxonomía ordenadora de nuestras observaciones. Presentismo, localismo y reduccionismo son las categorías que nos permiten clasificar y analizar

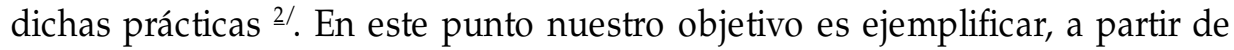
nuestra experiencia, cada uno de estos casos, añadiendo los matices correspondientes. En el último apartado de este trabajo mostraremos cómo cada una de las prácticas descritas significa el sacrificio de la especificidad del conocimiento histórico.

Presenteismo es 'la tendencia a limitar la enseñanza de la historia sólo a los períodos más recientes', tras de lo que habría motivaciones 'groseramente utilitaristas': 'prevenir el fracaso escolar comprimiendo los contenidos'. El presentismo introduciría una discontinuidad entre pasado y presente -tendiendo a una pura descripción del funcionamiento del mundoimpidiendo así cualquier 'explicación genética'. Retomando la conocida indicación de Bloch, se induciría a una total incomprensión del presente a causa de la ignorancia del pasado. Un primer matiz: es sabido que los períodos recientes no son un terreno cómodo para nuestros profesores de historia, significa de inmediato riesgos y conflictos. Pensando en Historia de Chile, la práctica más extendida es la de usar la sobrecarga de contenidos y escaso tiempo como argumento de la omisión del tratamiento de la historia reciente en el aula. Dado que sigue imperando, tanto en programas como en la formación misma de los docentes, un criterio puramente cronológico (que estructura la historia en base a un tiempo lineal 'homogéneo y vacío'), el estancamiento en las características del período oligárquico, por ejemplo, usualmente justifica el que a fin de semestre se avance sólo hasta los gobiernos radicales.

En nuestra realidad escolar el presentismo se efectúa igualmente, pero de otras maneras. Si el efecto fundamental del presentismo es la total incomprensión del presente (y sabemos que se puede reproducir una 
descripción sin comprender nada) con su secuela añadida de 'merma en la capacidad de reacción y respuesta frente a los hechos que afectan al ciudadano', el presentismo se puede efectuar mediante las descripciones lineales que predominan aun hoy. La descripción del pasado redunda en presentismo si se lo desconecta del presente y, por tanto, se lo priva de toda función explicativa. La división del pasado en períodos, con la correspondiente enumeración de rasgos propios, personajes y logros, responde mejor a las necesidades de una Prueba de Selección Universitaria que a las de una formación ciudadana. Y está claro que la mayor parte de los colegios privilegia lo primero: a mayores puntajes exhibidos publicitariamente, mayor matrícula. La competencia por la conquista de clientes coacciona fuertemente el quehacer en el aula.

Demás está señalar que las opciones van mucho más allá del orden cronológico de contenidos. El trazar un perfil de problemas de la actualidad, para luego hacer sus respectivas genealogías, es una opción mucho más estimulante intelectualmente que el cuento de la historia desde y hasta, sin dejar de propiciar a los estudiantes una erudición mínima. La falta de una explicación propiamente histórica es solidaria de la tendencia a naturalizar la historia.

Localismo es la práctica que nace 'con el concepto piagetiano de pensamiento concreto, que impone la absoluta prioridad de la aproximación a la realidad inmediata como método didáctico', es decir, 'la secuencia de lo cercano a lo lejano para organizar los contenidos de la enseñanza'. Esto ha significado en nuestro medio la introducción de experiencias inducidas de historia local, barrial o familiar. Conviene andar con cuidado en este punto, ya que, como es sabido, tales apuestas en nuestro país fueron introducidas -al menos en el campo de la investigación social e historiográficaen el contexto del trabajo de ONGs que trataron de desplegar estrategias de resistencia a la dictadura de Pinochet. Tales prácticas, se podría suponer, son por definición progresistas; pero su rendimiento en la experiencia escolar parece ser otro hoy.

Dando por sentado el riesgo de presentismo (en el sentido original de Martinez-Shaw) que conlleva el trabajo exclusivo con la oralidad en que se sustentan preferentemente estas experiencias, podemos sumar el de la confianza irrestricta en la memoria que, junto con aportar información importante, es también la fuente de lugares comunes y terreno preferente de lo que en un sentido amplio podemos denominar ideología. La tan humana escala familiar y barrial es ante todo hoy -por ejemplo, a causa del determinante influjo de los medios- un campo privilegiado para la reproducción y 
reforzamiento de preconcepciones ${ }^{3 /}$. Lo mejor que puede hacer con esos relatos el docente es poner esas experiencias en contraste en el aula, para inducir un extra na miento productivo en los alumnos. Posibilidad condicionada a la disposición de una heterogeneidad social y cultural suficientemente amplia al interior del grupo curso. (El dato es que nuestras escuelas se van transformando más en ghettos que en espacios pluriclasistas o pluriculturales).

La historia local -incluso en sus versiones académicas- suele tener como inicio y fin puramente lo local. Se queda en el relato micro, cuando no en lo meramente anecdótico, conllevando efectos alienantes y contrarios a un conocimiento histórico fiable o útil socialmente. Valga la cita de Hobsbawm en este punto: "El principal peligro es la tentación de aislar la historia de una parte de la humanidad -la del propio historiador, por haber nacido en ella o haberla elegido- del contexto más amplio" (Hobsbawm, 1998, p. 269). El peligro al que alude Hobsbawm tiene que ver con la renuncia al conocimiento, pues no se puede tener una cabal comprensión de lo local si no es en conexión con procesos mayores de los que lo local es parte, manifestación o excepción. En síntesis: no reestablecer el nexo entre lo particular y lo universal significa quedarse preso en la pura perplejidad. La recuperación del pasado así planteado se queda en el gesto estetizante sin generar conocimiento, no añade complejidad a los cuadros del pasado, ni sirve a la hora de trazar mapas fiables para la acción. Así la historia local se encontraría más cerca de la 'industria de la memoria' que de la historiografía. Más lejos nos llevaría la consideración del patrimonio local, toda vez que termina en la confección de un inventario de casas de gente importante o de objetos antiguos descontextualizados de sus usos originales.

Reduccionismo es el acto deliberado de selección de tan sólo un orden de hechos a la hora de generar descripciones y explicaciones históricas, lo que implica asumir 'la historia total como mero desiderátum, imposible de atender en la práctica cotidiana de los docentes'. Coincidiendo con las constataciones de Martinez-Shaw, dicho orden de hechos perpetúa el viejo positivismo historiográfico, en base a centrar las explicaciones en hechos políticos, esto es, en la práctica, decisiones de individuos sobre la base de su genio, pequeñez, altruismo o egoísmo. Otras tantas veces la reducción se efectúa desde el otro extremo: mediante la apuesta por unos datos geográficos, económicos $-\mathrm{y}$ hasta geopolíticos-, reflejos de una absoluta determinación extrahistórica. En nuestras observaciones este vicio redunda en dos versiones igualmente unilaterales: el genio político ya aludido y, su presunta alternativa o corrección, el determinismo económico. Esto por oponer las prácticas de enseñanza más tradicionales con las de pretensiones políticas progresistas. 
Pero en nuestro medio hace ya tiempo que se viene impulsando un tipo de localismo y reduccionismo histórico desde los medios de comunicación, que ha tenido como aliciente la pregunta por nuestra identidad en el contexto del bicentenario. Expresión directa de ello ha sido el despliegue de las perspectivas pa trimonial y monumental, en sus más diversas versiones. Entre las tradicionales están las ligadas a los grandes hombres, las grandes familias forjadoras de la patria, o los héroes. Entre las más innovadoras -y legitimadas por una renovación historiográfica proveniente del primer mundo, con todas las credenciales- están las que levantan acta de la vida cotidiana o la vida privada de otras épocas, lo que -independiente de su rendimiento disciplinario- en el aula se traduce usualmente en un interés por las costumbres, las comidas, la música, los bailes, etc. (Téngase presente las iniciativas sobre grandes hombres y la vida privada canalizadas por el periódico El Mercurio) ${ }^{4}$. La selección y uso unilateral de las acciones de los grandes hombres, las costumbres de la vida cotidiana o las determinantes económicas, como hechos relevantes históricamente, obstruyen la comprensión del sentido que pueda tener dedicarse al estudio del pasado detrás de un mar de detalles y anécdotas, o en una serie de factores que se escapan de la voluntad organizada de los hombres.

En todos los casos descritos podemos observar el asentamiento de una serie de ideas y juicios que redundan en una total desconexión entre pasado y presente. Sencillamente el pasado no logra explicar el presente. Así, aunque los estudiantes de niveles superiores acepten como verosímil el planteamiento acerca de que el presente es resultado del pasado, mientras no logren la experiencia de entender su propio presente de esa manera (o mejor aún, su futuro como produciéndose en este presente), se seguirá contribuyendo a una deshistorización del presente, es decir, a su naturalización.

Nada hay de histórico en el puro gusto exotista por el pasado. El historiador se ocupa del pasado porque le urge el presente. Descartar esta idea fundamental de las prácticas de la enseñanza de la historia es disolver en ellas la especificidad del conocimiento histórico y pervertir su uso social.

\section{LA OPERACIÓN HISTORICA}

La historiografía tiene, desde inicios de su constitución disciplinaria a mediados del siglo XIX, una vocación crítica del presente. Sea en la función advertida por Ernest Renan (2000), reivindicando el trabajo erudito que daba las pruebas de la violencia en la que se fundaba toda unidad nacional, es decir, recordando más de lo que la memoria oficial de un presente quisiera. 
O bien en la operación reivindicada por Marx en Miseria de la Filosofía, indagando el pasado para tramar una genealogía que revelaba la contingencia que estaba a la base de un presente de explotación capitalista que se pretendía hacer pasar como el cumplimiento de las leyes de la Naturaleza.

"El olvido, incluso diría que el error histórico, son un factor esencial en la creación de una nación, y de aquí que el progreso de los estudios históricos sea frecuentemente un peligro para la nacionalidad. La investigación histórica, en efecto, ilumina los hechos de violencia ocurridos en el origen de todas las formaciones políticas, incluso aquellas cuyas consecuencias han sido más benéficas. La unidad siempre se hace brutalmente" (Renan 2000, p. 56).

"Los economistas tienen una manera singular de proceder. Para ellos no hay más que dos clases de instituciones: las del arte [artificiales] y las de la naturaleza. Las instituciones del feudalismo son instituciones artificiales, y las de la burguesía son instituciones naturales. En lo cual se parecen a los teólogos, que establecen también dos clases de religiones: toda religión que no es la de ellos es una invención de los hombres, al paso que su propia religión es una emanación de ${ }^{\circ}$ Dios. Al decir que las relaciones actuales -las relaciones de la producción burguesa- son naturales, los economistas dan a entender que son relaciones dentro de las cuales se crea la riqueza y se desenvuelven las fuerzas productivas con arreglo a las leyes de la Naturaleza. Luego esas relaciones son, a su vez, leyes naturales independientes de la influencia de los tiempos; son leyes eternas que deben regir siempre la sociedad. De suerte que la Historia ha existido, pero ya no existe. Ha habido Historia, puesto que han existido instituciones feudales, y en esas instituciones se encuentran relaciones de producción enteramente distintas de las de la sociedad burguesa, que los economistas pretenden dar por naturales, y por lo tanto, eternas" (Marx 1999, p. 137).

La historiografía es una herramienta que ilumina los sujetos, los proyectos, las luchas y los intereses que se han tejido para dar origen a lo que llamamos presente. La historia recurre al pasado sólo porque le interesa el presente; éste es la cantera de donde extrae sus asombros y preguntas (lo que nos puede conducir a cualquier época pasada). La curiosidad gratuita por el ¿cómo era antiguamente? puede encaminarse con los métodos usados por la historiografía, pero el saber histórico no fue concebido para ello, sino para que los hombres y mujeres se expliquen su presente, salgan de él, produzcan historia: la historiografía como garante de la historicidad humana: "el saber histórico constituye la iluminación privilegiada gracias a la cual la práctica humana afirma su poder" (Chatelet, 1989, p. 53). 
Ningún presente exige más historia que aquel en que parecen impensables otras alternativas de futuro. En donde el discurso del poder manda a reproducir lo existente -cuando se genera consenso en torno a cual debe ser nuestro futuro- la historiografía recuerda que cada presente-pasado ha sido el escenario en el que han luchado una diversidad de sujetos, que este presente en el que (mal) habitamos es la concreción del proyecto de otro, pero que puede ser también el lugar para levantar proyectos para que el futuro no sea -en otra versión- la repetición del presente. En contra de un recurrente sentido común podemos afirmar que no es natural que unos vivan bien y otros mal, que unos se enriquezcan y otros se hagan más pobres (nada de esto está determinado por una supuesta naturaleza humana: la historia misma y la etnología nos han colmado de formas de organización social llenas de dispositivos para evitar el abuso y la pauperización de los individuos).

Pero la avalancha de productos seudohistoriográficos de la industria cultural, tanto como las malas prácticas de la enseñanza de la historia, a las que nos vemos expuestos cotidianamente, tienden a devaluar la función historiadora (Chatelet, 1989). La historiografía, de ser una herramienta para comprender y salir del presente, se ha convertido en un repertorio de técnicas para embalar productos culturales, junto con perpetuar aquella forma escolar de un relato que no logra hacernos sentido.

Y es que la historiografía no se define por sus métodos -después de todo casi ninguno le pertenece: la critica de documentos la ha tomado en su origen de la filología y la diplomática, el análisis de balanzas de pagos y ciclos, de la economía, y así otros de la geografía, demografía, etc. Lo que queremos señalar es que este saber no halla su especificidad tan sólo en el acto de establecer los hechos 'como realmente ocurrieron', sino en las preguntas, explicaciones y funciones que es capaz de efectuar: la operación histórica (de Certeau, 1985).

¿Qué preguntas son esas? Pues las preguntas que corresponde hacerse ante las dificultades o extrañamientos de cada presente. ¿Cómo se ha constituido este presente? ¿Por qué estos niveles de desigualdad? ¿Por qué la exclusión de los pueblos indígenas? ¿Por qué esta crisis económica global?. Son las preguntas de un historiador del mundo contemporáneo. Pero no menos ajeno al presente es el historiador del mundo antiguo, piénsese en Jean-Pierre Vernant cuando historiaba el pensamiento antiguo griego tratando de desentrañar los orígenes de una racionalidad puesta en duda luego de las aberraciones desplegadas desde mediados del siglo XX (Vernant, 1993), o indagando en los arquetipos de nuestra relación con la alteridad (Vernant, 
2001). La pregunta determina la profundidad temporal del trabajo del historiador.

Como ha sostenido recientemente Enzo Traverso, “...para escribir un libro de Historia que no sea sólo un trabajo aislado de erudición, hace falta también una demanda social, pública" (Traverso, 2007, p. 40). Y si esas preguntas no surgen de la sociedad, el historiador debe interpelarla formulándolas.

¿Qué explicaciones formula el historiador? Cada pregunta nos hace indagar en materiales de distintos tiempos y niveles de la vida social. El historiador trabaja con huellas que han dejado sujetos de otro tiempo. El historiador recompone la acción de cada sujeto en medio de estructuras dadas que son producto también -en mayor o menor medida- de la acción humana, va tramando sus encrucijadas: una acción se encuentra con otra, luchan, se anulan, hacen alianza excluyendo a otros que forman nuevos proyectos, etc. Se verá entonces por qué el historiador se ve obligado a producir un relato para explicar (como insistiera Paul Ricoeur). La mayor parte de las veces éste tiene la estructura de una "genealogía del presente", es decir, muestra por qué, debido a qué acciones e intereses el presente ha llegado a ser lo que es. Pero como es siempre fruto de la acción humana -una construcción de sujetos en pugna- nunca sella el juicio de que el presente es inmodificable. Al contrario, al restituir los proyectos que competían en el pasado por un futuro que hoy habitamos como el presente, nos hace comprender que éste siempre pudo ser otra cosa, que el actual orden descansa en elementos absolutamente artificiales, humanos. El presente no es siempre la mejor opción que se barajaba en el pasado.

Hemos hecho pasar la especificidad de la historia por sus preguntas y modos de explicación, pero no para descartar de plano sus métodos (el énfasis ha sido necesario para criticar el tan extendido y unilateral concepto de la historia como un saber que se limita a establecer hechos).

En una primera instancia, el motivo por el cual -en contra de toda apuesta ficcionalista- no se debe abandonar el trabajo riguroso del establecimiento de los hechos, no tiene que ver con que el relato deba terminar siendo una suerte de espejo de lo real-pasado, sino con que de otra manera negociaremos con menos éxito con lo real. El reparto de la responsabilidad de las acciones y proyectos, como el seguimiento de las estrategias de los diversos sujetos, de ser mal establecidos nos conducirán igualmente a una desorientación en nuestro presente. En lo que se refiere al conocimiento del pasado, la historia es lo mejor que tenemos, han establecido recientemente un grupo de investigadores en teoría historiográfica (Brauer, 2009). 
En una segunda instancia, el buen establecimiento de los hechos sigue siendo importante porque ¿con qué nos relacionamos si aquello que se nos ofrece como pasado en realidad no aguanta constatación ni prueba alguna? Si no nos relacionamos con el pasado lo hacemos con nosotros mismos, con proyecciones de nuestra propia cultura. En estricto rigor, la actual vuelta del pasado a la que nos tiene acostumbrados la industria cultural (telenovelas, novelas históricas, films, parques temáticos, etc.) no lo es de sus restos o huellas sino de sus simulacros: "la copia idéntica de la que jamás ha existido original", "el pasado como referente se encuentra puesto entre paréntesis, y finalmente ausente, sin dejarnos otra cosa que textos" (Jameson, 1995). Esas mercancías culturales, preponderantemente imágenes y películas, lejos de representar el pasado, encarnan las ideas y estereotipos de nuestra propia sociedad. A esto Fredric Jameson ha llamado "historia pop" ${ }^{5}$.

Se podrá entender, entonces, cual es la real importancia de establecer lo mejor posible los hechos: sin ese trabajo riguroso -que va más allá de la reconstrucción de edificios, utensilios, ropas, comidas y armas de época- no sabremos cuál era esa imagen del mundo que tenían aquellos que nos antecedieron, qué batallas dieron y en nombre de qué, cuáles eran sus valores y concepciones de lo que debe ser una sociedad justa, una vida buena. Nada más sospechoso que una historia que nos muestra las épocas pasadas como otra versión de lo mismo que hoy tenemos. (Una historia a lo "Picapiedras" de Hanna-Barbera: ellos eran iguales a nosotros, con la única diferencia de que todo estaba hecho de piedra y madera. Es interesante constatar como esta violación de la especificidad del pasado es usada corrientemente como supuesto recurso didáctico para hacer más comprensible la historia a los estudiantes. Una extensión de lo que arriba denominamos como presentismo).

El pasado histórico ha de reconocerse por la perplejidad que nos causa derivada de su diferencia, de su inactualidad, por esa primera impresión de, ¿cómo podían pensar eso? ¿cómo podían luchar por aquello? ¿cómo pudieron dar forma a una sociedad así? ¿Por qué motivo ya no tenemos lo que ellos si? La historia nos interpela, nunca nos confirma en nuestro lugar: las cosas no fueron siempre así...; las cosas cambian de tanto en tanto...; y por eso este presente no será eterno. Como se verá, nuestro planteamiento no echa de menos tanto la posibilidad de narrar los hechos como realmente sucedieron, sino la diferencia del pasado y lo que se posibilita en términos de la comprensión de nuestro presente a partir de este extrañamiento. En una palabra, la historia nos hace concientes de nuestra historicidad, productos y productores de la historia: "el pasado es, ante todo, el medio de representar una diferencia. [...] la figura del pasado conserva su valor primero de representar lo que falta. Con un material que por ser objetivo, está 
necesariamente $a h i$, pero es connotativo de un pasado en la medida en que, ante todo, remite a una ausencia, esa figura introduce también la grieta de un futuro. Un grupo, ya se sabe, no puede expresar lo que tiene ante sí -lo que aún falta- más que por una redistribución de su pasado" (de Certeau, 1985, p. 53). De este modo nuestro habitual concepto de historia cambia su centro de gravedad del pasado al futuro (lo que falta).

Los historiadores (al menos cuando no están ocupados de dialogar entre ellos mismos, enfrascados en la pura erudición o tratando de sobrevivir, o lucrar, haciendo turismo y patrimonio) tanto como los profesores de historia "pueden sacar el pasado del dominio de lo trivial y lo nostálgico y comenzar a generar la conciencia de la historia como el relato de la acción humana, las elecciones humanas, de la gente que trata de resolver sus relaciones sociales cambiantes -y muchas veces desiguales- en medio de sus circunstancias cambiantes y también, muchas veces, desiguales. Con esta comprensión del pasado podemos ser más capaces de enfrentarnos, inteligente y humanamente, con valor y con humildad, a los problemas muy reales que nos confrontan en el presente" (Shopes, 1993, p. 251).

\section{CONSIDERACIONES FINALES (TENTATIVAS HACIA UN CAMBIO CONCEPTUAL)}

Entendemos aquí el cambio conceptual como aquel proceso en que se rebasan los límites del conocimiento previo o del sentido común. A su vez el cambio conceptual depende, en el contexto educativo, de una intervención didáctica que entendemos como la estrategia tanto de elección de contenidos como de la modalidad de trabajarlos, para producir un cierto desajuste al interior del sistema del conocimiento previo, es decir, unos procesos caracterizados por la contradicción entre el sistema y la presentación de nuevos fenómenos, realidades y experiencias, produciendo la desestabilización de los elementos que lo conforman, lo cual se posibilitaría, según las investigaciones de Aisenberg (cit. en Castorina, 2007) mediante el planteo de situaciones problemáticas realizadas en actividades de clase. Hay que destacar, no obstante, que la mayor dificultad de esta empresa la constituye el hecho de que el conocimiento previo está conformado como un sistema, por lo que es estéril trabajar sobre unas ideas aisladamente.

Dada la estructuración del conocimiento previo, nuestra actividad apunta a presentar también la conexión entre las siguientes tres ideas: la utilidad de la historia para entender el presente, pero no sólo por proporcionarnos los datos necesarios, sino por el tipo de conocimiento que produce, como ya lo 
hemos explicitado. Más aún, el conocimiento histórico muestra la necesidad de intervenir el presente, pues en esa ida y venida del pasado al presente muestra lo que falta, la ausencia, la pérdida, los proyectos de futuro posibles del pasado, pero que habitualmente un acto de violencia imposibilitó. La actividad del historiador es crítica en tanto diferenciadora: accede al pasado de una manera específica y en su labor interpretativa construye un conocimiento que es tal en la medida que rompe con un saber que es sentido común sobre el pasado. El historiador muestra usualmente que antaño las cosas no eran como hoy, pero esa diferencia no es mero exotismo del pasado, pues ha de narrarnos cómo es que las cosas llegaron a ser lo que son y por qué otras, pudiendo, no llegaron a ser. Este es el sentido de lo establecido por el arriba citado Michel de Certeau: "La figura del pasado conserva su valor primero de representar lo que falta" ha sostenido, y esto significa siempre medirse con el presente.

Dado que nuestro grupo-curso de referencia está conformado por alumnos universitarios, nos hemos permitido conservar algunos métodos tradicionales (librescos, necesarios incluso a propósito de una asignatura de Introducción a la Historia), no perdiendo de vista que la introducción de conceptos e ideas disciplinarias deben estar en conexión con las realidades presentadas y con las experiencias de los alumnos.

La actividad trata de hacer una comparación entre las formas de comprender el presente, en el pasado y en la actualidad. Para esto último el sustrato usado son las visiones -descritas ya al inicio de este texto- que los mismos alumnos han entregado. En este ámbito podemos hablar de conocimiento previo, como representación social, y dentro de éste de hipótesis, particularmente en lo que respecta a la explicación que aventuran sobre, o más allá, de los problemas observables en el presente.

Esta perspectiva se trabaja en consonancia con un texto, ¿El fin de la historia? de Francis Fukuyama (1990), que es el artículo que precedió su libro El fin de la historia y el último hombre. Como lo ha constatado la propia historiografía (Fontana, 2002), en este texto el autor efectúa una legitimación del actual orden (liberal-capitalismo y todo el concierto de conductas humanas implicadas) extendido a escala planetaria, presentándolo como el último escalón evolutivo de la sociedad e inmunizándolo de su carácter histórico, o sea transitorio, y desestimando la eficacia de los acontecimientos humanos que vayan en dirección de propiciar un nuevo orden. En esta primera fase de la actividad se logra la identificación, o bien el distanciamiento de los estudiantes que tienen una inclinación ideológica alternativa, ya que el texto es muy explícito respecto del orden que defiende. 
La segunda fase de la actividad está dada por el trabajo de un segundo texto, Capitalismo e historia: la escuela escocesa, que es el capítulo IV de Historia. Análisis del pasado y proyecto social del historiador español Josep Fontana (1982). En términos sintéticos acá se expone sistemáticamente cómo es que la burguesía inglesa, luego de su llegada al poder mediante lo que llamó la Gloriosa Revolución, generó primero una alianza con la nobleza en contra de los sectores radicales, para luego generar una visión de la historia y la sociedad que mostraba las relaciones fundadas por el capitalismo -que cada vez más marcaban aquel presente- como la conclusión de una evolución natural de tipo económica, lo que contribuyó no sólo a hacer aceptable el presente por parte de los sectores marginados, sino también a censurar la eficacia histórica de la acción humana (revolución) tras supuestas leyes naturales que provocan el cambio y mantienen un orden natural, prescindiendo de ella.

La actividad aspira a producir un efecto de contraposición de los dos casos tratando de establecer una continuidad de las estrategias de dominación, a nivel de las representaciones sociales, necesarias para la reproducción del capitalismo. La historia como disciplina es la que posibilita esta operación, pues nos indica cómo ese pasado que podemos iluminar como un campo de tensión -de lucha, de disputa de intereses, intenciones, acciones realizadas o frustradas- terminó con el triunfo de unos sujetos sobre otros, o con la resolución de los conflictos pactados políticamente, produciendo así el futuro de esa sociedad. Nuestro presente, entonces, no ha sido producto de un proceso diferente, de lo que se sigue que en este mismo presente se están produciendo los movimientos que darán forma a un presente-futuro: "la historia, si no la hacen unos sujetos, la hacen otros sujetos" (Zemelman, 2001, p. 319). Claro que esta perspectiva sólo es efectiva en la medida que contemplemos una práctica historiográfica que ponga en un lugar central a los sujetos, y que no sostenga que la historia escrita es una posible ficción.

Aunque nuestro ejemplo resulte en extremo reducido y simplificado, sirva al menos como referencia de la dirección en que creemos se debe trabajar para provocar contradicción con los elementos de un conocimiento previo que tiende a naturalizar el presente desestimando las entradas para su comprensión y proyección. 
El presente trabajo ha tratado de dar una mirada reflexiva sobre una práctica y a partir de este ejercicio buscar la manera de mejorarla. Han sido fundamentales las herramientas teóricas de los enfoques tanto cognitivos como constructivistas, a partir de los que hemos introducido algunos conceptos. A este nivel-conceptual- la formulación básica podría sintetizarse de la siguiente manera: el conocimiento previo es el sustrato sobre el cual actuar con una intervención didáctica para propiciar el cambio conceptual. No obstante, dicha intervención debe considerar la sistematicidad de los contenidos del conocimiento previo diseñando una actividad que trabaje sobre varias ideas también de manera sistemática, teniendo como eje central la experiencia del alumno para que este nuevo conocimiento le haga sentido.

Hemos proporcionado en la última parte un ejemplo de actividad del tipo arriba señalada, la que contempla algunas acciones ya estrenadas. Vale la pena destacar que la condición de posibilidad del ejercicio planteado está dada por el recurso de una historiografía crítica, que desestime el tratamiento del devenir humano como el despliegue de las conductas del homo economicus, para presentarlo verosímilmente como el despliegue de la acción humana, en donde la organización política tiene un rol fundamental.

Sin embargo, como lo ha sugerido Mario Carretero, quizá la mayor aspiración que podamos mantener es que los alumnos aprendan historia. Citamos esta idea no como forma de desdecir toda nuestra argumentación, sino para dejar planteada la pregunta acerca de si una experiencia didáctica como ésta -por sí sola- podría lograr que los estudiantes se posesionaran en la cotidianeidad de su presente como agentes, cuestión que se revela, al menos en nuestro actual contexto, improbable dados la permanencia y el peso de un sistema político y un modelo económico, y un modo de vida que solidariza con el sentido común. La educación no puede por sí sola lo que hace la política: el cambio de una sociedad, la construcción de un proyecto. Cabe entonces postular en este último sentido la enseñanza de la historia como una labor pre-política (para-la-política). Desde luego no se trata de postular -otra vez- la educación como un campo autónomo, sino de partir reconociendo en nuestra actividad hasta dónde se puede llegar. De lo contrario la labor docente, por bien intencionada que se conduzca, seguirá signada por la frustración y la impotencia. O una alternativa peor: la autocomplacencia de quien cree hacer política enseñando historia. 


\section{NOTAS}

1. Parte de los contenidos de este apartado han sido elaborados en el contexto del curso de postgrado "Enseñanza de las Ciencias Sociales: construcción del conocimiento y actualización disciplinar". Dirigido por Mario Carretero, FLACSOArgentina, 2007. Pese a esto los contenidos no han sido publicados y poseen carácter inédito.

2. Otro tanto ha aportado en este sentido Carlos Antonio Aguirre Rojas en su libro Antimanual del mal historiador, (Montesinos, Barcelona, 2007). Fundamentalmente en el capítulo II, Los siete (y más) pecados capitales del mal historiador.

3. En otro lugar he sostenido: "Pero la historia local (socializante) se nos quiere presentar también como una práctica democrática liberada tanto de las formalidades y monopolio metodológico de la disciplina historiográfica como de la vigilancia academicista. Lo que ha dado paso a la fábula de que la historia local es un saber al margen del poder. (Como si la oralidad fuera garantía de la autonomía del recuerdo, como si las políticas comunicacionales o el mercado no nos indicara qué es lo digno de ser recordado)". Ver: Aravena, Pablo, Memorialismo, historiografía y política. El consumo del pasado en una época sin historia, Ediciones Escaparate, Concepción, 2009.

4. Nos referimos a los proyectos editoriales "Chilenos del Bicentenario. Los Hombres y las Mujeres que Cambiaron Nuestra Historia" el año 2007 (coordinado por Gonzalo Vial y auspiciado por la Universidad Santo Tomás) y "Chile en Cuatro Momentos" el año 2009 (proyecto del Departamento de Historia de la Universidad de Los Andes, financiado por el Grupo Enersis). Este último elaborado con el expreso objetivo de que la gente "comience a querer ese pasado al conocer su vida cotidiana", "con imágenes inéditas que dan a conocer el día a día de cada época", según declaraciones de su Director Francisco Javier González (En: http://www.uandes.cl/ vida-universitaria/entrevista-director-chile-en-cuatro-momentos-2.html) No deja de llamar la atención cómo los grupos conservadores y tradicionalistas chilenos se mueven cómodamente entre estos dos extremos de la historiografía: el positivismo decimonónico y la presunta renovación disciplinaria asociada a la vida cotidiana y privada. No sin mediar una peculiar reinterpretación de aquel proyecto iniciado por Philippe Aries y Georges Duby, que termina asociando la propuesta a un positivismo de la vida cotidiana.

5. Me he referido a este fenómeno en mi libro: Memorialismo, historiografía y política. El consumo del pasado en una época sin historia, Ediciones Escaparate, Concepción, 2009. Para una aplicación de estas consideraciones a la gestión patrimonial, ver Pablo Aravena y Mario Sobarzo, Valparaíso: patrimonio, mercado y gobierno, Ediciones Escaparate, Concepción, 2009. 


\section{REFERENCIAS BIBLIOGRÁFICAS}

Bourdieu, P., 1991

Bourdieu, P.,

J.-C. Chamboredon

\& J-C. Passeron, 1994

Brauer, D. (ed.), 2009

Burke, P., 2006

Carretero, M. y

J. Pozo, 1984

Carretero, M., 2007a

Carretero, M., 2007b

Castorina, J. A., 2007
Language and symbolic power. Harvard University Press, Cambridge.

El oficio del sociólogo, Siglo veintiuno editores, México.

La historia desde la teoría. Una guía de campo por el pensa miento filosófico acerca del sentido de la historia y del conocimiento del pasado, Vol. I y II, Prometeo, Buenos Aires.

La revolución historiográfica francesa: la escuela de los Annales: 1929-1989, Gedisa, Barcelona.

¿Enseñar historia o contar historia? Otro falso dilema. En: Revista Cuadernos de Pedagogía $\mathrm{N}^{\mathrm{N}}$ 111, Barcelona.

Principales aportes de las investigaciones cognitivas a la enseñanza de las ciencias sociales. Documento de trabajo, postgrado: Enseñanza de las Ciencias Sociales: construcción del conocimiento y actualización disciplinar (V Cohorte), FLACSO-Argentina.

Documentos de identidad. La construcción de la memoria histórica en un mundo global, Paidós, Buenos Aires.

Adquisición de conocimientos sociales en un programa constructivista. Documento de trabajo, postgrado: Enseñanza de las Ciencias Sociales: construcción del conocimiento y actualización disciplinar (V Cohorte), FLACSO-Argentina. 
Chatelet, F., 1989

Cruz, M., 1986

Cruz, M., 2004

de Certeau, M., 1985

Fontana, J., 1982

Fontana, J., 2002

Fukuyama, F., 1990

Jameson, F., 1995

Hobsbawm, E., 1998

Lorenz, F., 2007
El tiempo de la historia y la evolución de la función historiadora. En: Chatelet, F., Preguntas y réplicas. En busca de las verdaderas semejanzas, Fondo de Cultura Económica, México, pp. 21-53.

Narratividad: la nueva síntesis, Península, Barcelona.

Tiempo de narratividad (el sujeto, entre la memoria y el proyecto). Cuadernos del Taller de Epistemología Social N ${ }^{\circ}$ 2. Facultad de Humanidades, Universidad de Valparaíso, Valparaíso.

La operación histórica. En: J. Le Goff y P. Nora, (comp.), Hacer la historia, Editorial Laia, Barcelona.

Historia. Análisis del pasado y proyecto social, Crítica, Barcelona.

La historia de los hombres: el siglo XX, Crítica, Barcelona.

¿El fin de la historia? En: Estudios Públicos, $\mathrm{N}^{\mathrm{O}}$ 37, Centro de Estudios Públicos, Santiago.

El posmodernismo o la lógica cultural del capitalismo avanzado, Paidós, Barcelona.

La historia de la identidad no es suficiente. En: Sobre la historia, Crítica, Barcelona.

La historia como ciencia social: ¿mirar a las sociedades o los individuos? Documento de trabajo, postgrado: Enseñanza de las Ciencias Sociales: construcción del conocimiento y actualización disciplinar (V Cohorte). FLACSO-Argentina. 
Martinez-Shaw, C., 2004 La historia total y sus enemigos en la enseñanza actual. En: Carretero, M. y Voss, J. F. (ed.). Aprender y pensar la historia, Amorrortu, Buenos Aires.

Marx, K., 1999

Miseria de la filosofía. Contestación a la "Filosofía de la miseria" de Proudhom, Ediciones Folio, Navarra. (Publicada originalmente en 1847).

Renan, E., 2000

¿Qué es una nación? En: Fernández Bravo, Á. (ed.), La invención de la nación. Lecturas de la identidad de Herder a Homi Bhabha, Manantial, Buenos Aires, pp. 53-66.

(Conferencia dictada en 1882).

Rosa Rivero, A., 2004

Memoria, historia e identidad. Una reflexión sobre la enseñanza de la historia en el desarrollo de la ciudadanía. En: Carretero, $\mathrm{M}$. y Voss, J. F (ed.). Aprender y pensar la historia, Amorrortu, Buenos Aires.

Shopes, L., 1993

Más allá de la trivialidad y la nostalgia: contribuciones a la construcción de una historia local. En: Aceves Lozano, J. (Comp.), Historia Oral, Instituto Mora / UAM, México.

Traverso, E., 2007

Vernant, J.-P., 1993

Mito y Pensamiento en la Grecia Antigua, Ariel, Barcelona.

Vernant, J.-P., 2001

La muerte en los ojos. Figuras del otro en la antigua Grecia, Gedisa, Barcelona.

Zemelman, H., 2001

El rescate del sujeto. La reflexión epistemológica en América latina. En: Revista de Ciencias Sociales N ${ }^{\circ}$ 46, Facultad de Derecho y Ciencias Sociales, Universidad de Valparaíso, Valparaíso. 